\title{
DESIGN BASED ON DUCTILE-BRITTLE TRANSITION TEMPERATURE FOR API 5L X65 STEEL USED FOR DENSE $\mathrm{CO}_{2}$ TRANSPORT
}

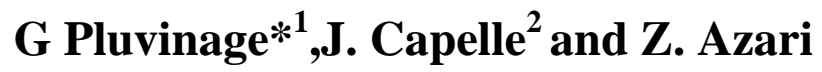 \\ 1.Fiabilité Mécanique. Conseils Silly sur Nied France \\ 2. LABPS. ENIM Metz France \\ * Corresponding author : pluvinage@,cegetel.net
}

\begin{abstract}
Safe and reliable transport of dense $\mathrm{CO}_{2}$ by pipes needs a careful choice of the constitutive pipe materials to prevent brittle crack propagation after ductile or brittle failure initiation. This unexpected phenomenon can occur after failure or leak promoted by external interferences. In this case, the rapid decompression of dense $\mathrm{CO}_{2}$ into gas leads to a very low local temperature of about $-80^{\circ} \mathrm{C}$.

To prevent risk of brittle fracture initiation and propagation, the material must remain ductile at this temperature. In other terms, its ductile-brittle transition temperature (DBTT) has to be lower than $-80^{\circ} \mathrm{C}$ minus a margin.

It is admitted that the DBTT is not a material characteristic but depends on specimen geometry, loading rate and loading mode, i.e. on constraints. A loss in constraint leads to a lower brittle-ductile transition temperature.

In order to select a steel for transportation of dense $\mathrm{CO}_{2}$, transition temperatures $\mathrm{T}_{\mathrm{t}}$ (from tensile test), $T_{K 27}$ and $T_{K 50}$ (from Charpy test) and $T_{K 100}$ (from fracture mechanics test) have been determined on an API 5L X65 pipeline steel. These transition temperatures have been reported versus a constraint parameter, e.g. T-stress, in a master curve. Differences between different brittle-ductile transition temperatures and temperature corresponding to T-stress acting in a pipe submitted to internal pressure on the master curve, give an estimation of the conservatism of the chosen reference transition temperature.
\end{abstract}

Key words: transition temperature, pipe steel API 5L X65, constraint, T-stress, $\mathrm{CO}_{2}$ transportation

\section{INTRODUCTION}

According to temperature and pressure, $\mathrm{CO}_{2}$ is present in 3 distinct states. $\mathrm{CO}_{2}$ is in a supercritical phase with temperatures higher than $31.1^{\circ} \mathrm{C}$ and pressures higher than $7.38 \mathrm{MPa}$ (values of the critical point). For conditions of temperature and pressure lower than these values, $\mathrm{CO}_{2}$ will be in a gas, liquid or solid state. Beyond its critical point, carbon dioxide enters a phase called supercritical. Dense $\mathrm{CO}_{2}$ transport is mainly performed by pipeline. Only in the United States, the existing national $\mathrm{CO}_{2}$ pipeline infrastructure dedicated primarily to deliver $\mathrm{CO}_{2}$ for enhanced oil recovery (EOR) comprises 3900 miles, and an extended national $\mathrm{CO}_{2}$ pipeline system is forecasted with the implementation of carbon dioxide capture and storage (CCS)-derived emission reductions. The entire system could be comprised between 11,000 and 23,000 additional miles dedicated $\mathrm{CO}_{2}$ pipeline before 2050 and dependent upon the hypothetical climate stabilization policies adopted [1].

Transport of $\mathrm{CO}_{2}$ in dense state presents a high potential for auto-refrigeration due to depressurisation, either during operations or due to equipment failure. 
The ductile-brittle transition temperature (DBTT), nil ductility temperature (NDT), or nil ductility transition temperature (NDTT) of a metal represents the point at which the fracture energy passes below a pre-determined value [2].

Design against brittle fracture considers that the material exhibits at service temperature, a sufficient ductility to prevent cleavage initiation and sudden fracture with an important elastic energy release. Concretely, this means that service temperature $T_{s}$ is higher than transition temperature $\mathrm{T}_{\mathrm{t}}$ :

$$
T_{s} \geq T_{t}
$$

Service temperature is conventionally defined by codes or laws according to the country where the structure or the component is built or installed.

A Fracture Mechanics based design ensures that stress intensity factor for design is lower than admissible fracture toughness and fracture toughness is greater than $100 \mathrm{MPa} \sqrt{\mathrm{m}}$ (i.e. the reglementary service temperature defined is above the reference temperature). This additional criterion is expressed by:

$$
T_{s} \geq R T_{t}+\Delta T
$$

where $\Delta \mathrm{T}$ is the uncertainty on reference temperature. This reference temperature $\mathrm{RT}_{\mathrm{i}}$ varies according to codes ( $\mathrm{RT}_{\mathrm{NDT}}$ or $\left.\mathrm{RT}_{\mathrm{T} 100}\right)$.

In this paper, a selected pipeline steel API 5L X65 is controlled by several mechanical tests in order to check if the material is eligible for dense $\mathrm{CO}_{2}$ transportation. The material has to satisfy a design based on transition temperature with a service temperature $\mathrm{T}_{\mathrm{s}}$ equal to $-80^{\circ} \mathrm{C}$ minus a $\Delta \mathrm{T}$, where $\Delta \mathrm{T}$ is a safety margin estimated to $8^{\circ} \mathrm{C}$ [3]. Due to the fact that different fracture tests give different transition temperatures, the choice of the most adequate test to provide a value close to the "structure or component" transition temperature $\mathrm{T}_{\text {struct }}$ is an open question. In addition, traditional design is based on transition temperature given by Charpy tests. Thus, it is necessary to know the degree of conservatism of this approach. For this purpose, three transition temperatures have been determined:

- transition temperature for elastic to elastoplastic behaviour in tension $T_{t}$,

- brittle to ductile transition temperature for Charpy $\mathrm{V}$ test $\mathrm{T}_{\mathrm{K} 27}$,

- fracture toughness transition temperature $\mathrm{T}_{100}$.

It is generally admitted that fracture resistance is sensitive to constraint. Consequently transition temperatures are affected as well. In order to evaluate the sensitivity to constraint of the abovementioned transition temperature, each transition temperature has been expressed as a function of T-stress [4], which is often used as a constraint parameter and determined by a master curve. This master curve allows determining the structure transition temperature $\left(\mathrm{T}_{\text {struct }}\right)$ and consequently the degree of conservatism of each abovementioned transition temperature.

\section{MATERIAL AND METHODS}

The investigated material is a pipeline steel API 5L X65 grade supplied as seamless tube with wall thickness equal to $19 \mathrm{~mm}$ and external diameter of $355 \mathrm{~mm}$. The typical chemical composition is given in Table 1, mechanical properties at room temperature are given in Table 2 .

Table 1. Typical chemical composition of pipe steel API 5L X65 (wt \%) [6].

\begin{tabular}{|l|c|c|c|c|c|c|c|c|c|c|c|}
\hline & $\mathrm{C}$ & $\mathrm{Si}$ & $\mathrm{Mn}$ & $\mathrm{P}$ & $\mathrm{S}$ & $\mathrm{Mo}$ & $\mathrm{Ni}$ & $\mathrm{Al}$ & $\mathrm{Cu}$ & $\mathrm{V}$ & $\mathrm{Nb}$ \\
\hline min. & 0.05 & 0.15 & 1.00 & - & - & - & - & 0.01 & - & - & - \\
\hline $\max$. & 0.14 & 0.35 & 1.50 & 0.020 & 0.005 & 0.25 & 0.25 & 0.04 & 0.080 & 0.080 & 0.040 \\
\hline
\end{tabular}


Table 2. Mechanical properties of pipe steel API $5 \mathrm{~L} \mathrm{X65}$ at $20^{\circ} \mathrm{C}$.

\begin{tabular}{|c|c|c|c|c|c|}
\hline $\begin{array}{c}\text { Yield stress } \\
\mathrm{R}_{\mathrm{e}} \\
(\mathrm{MPa})\end{array}$ & $\begin{array}{c}\text { Ultimate } \\
\text { strength } \\
\mathrm{R}_{\mathrm{m}}(\mathrm{MPa})\end{array}$ & $\begin{array}{c}\text { Elongation at } \\
\text { failure A \% }\end{array}$ & $\begin{array}{c}\text { Charpy Energy } \\
\mathrm{K}_{\mathrm{CV}} \\
(\mathrm{J})\end{array}$ & $\begin{array}{c}\text { Fracture Toughness } \\
\mathrm{K}_{\mathrm{Jc}}(\mathrm{MP} \sqrt{\mathrm{am}})\end{array}$ & $\begin{array}{c}\text { Hardness } \\
\mathrm{HV}\end{array}$ \\
\hline 465.5 & 558.6 & 10.94 & 285.2 & 280 & 205 \\
\hline
\end{tabular}

\subsection{Transition temperature for elastic to elastoplastic behaviour in tension $\mathbf{T}_{t}$}

Tensile tests at very low temperature exhibits brittle fracture and ductile failure at high temperature. At very low temperature, fracture always occurs at yield stress. This phenomenon was proven by compressive tests where no failure occurs, but yield stress is easily determined. When test temperature reaches transition temperature, failure occurs with plasticity at ultimate stress. In other words, transition temperature is defined when ultimate strength is equal to yield stress. Plasticity is a thermal activated process and yield stress decreases exponentially with temperature according to the following relationship:

$$
R_{e}=R_{e}^{\mu}+A \operatorname{Exp}(-B T)
$$

where $\mathrm{R}_{\mathrm{e}}{ }^{\mu}$ is a threshold, $\mathrm{A}$ and $\mathrm{B}$ are constants and $\mathrm{T}$ is temperature in Kelvin.

Similarly the ultimate strength decreases to temperature according to:

$$
R_{m}=R_{m}{ }^{\mu}+C \operatorname{Exp}(-D T)
$$

where $\mathrm{R}_{\mathrm{m}}{ }^{\mu}$ is a threshold, $\mathrm{C}$ and $\mathrm{D}$ are constants. Tensile tests have been performed on standard specimens in a temperature range $[120-293 \mathrm{~K}]$ with a strain rate of about $10^{-3} \mathrm{~s}^{-1}[6]$. Stress-strain diagrams have been recorded and the (static) yield stress and ultimate strength determined. Values of yield stress $R_{e}$, and ultimate strength $R_{m}$ are reported on Figure 1. Data are fitted with equation (3) and (4). Values of $\mathrm{R}_{\mathrm{e}}{ }^{\mu}, \mathrm{R}_{\mathrm{m}}{ }^{\mu}$ and constants $\mathrm{A}, \mathrm{B}, \mathrm{C}, \mathrm{D}$ are reported in Table 3. Yield stress value at $0 \mathrm{~K}$ is independent of loading rate and equal to $2320 \mathrm{MPa}$. This value is generally considered as equal to cleavage stress. Transition temperature is determined as the intersection of two curves at temperature $123 \mathrm{~K}$.

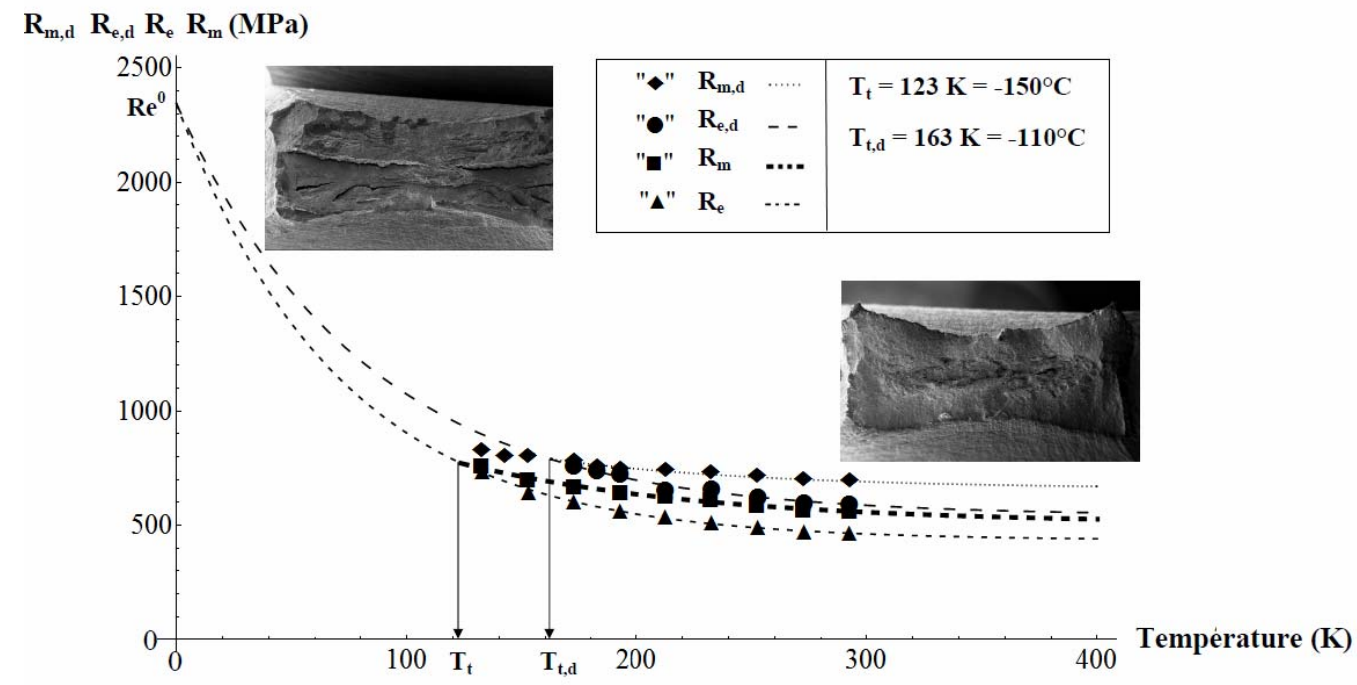

Figure 1. Evolution of static and dynamic yield stress and ultimate strength versus temperature for API 5L X65 pipeline steel. 
Table 3. Values of constants of equation (3) and (4) for API 5L X65 pipeline steel for static loading.

\begin{tabular}{|c|c|c|c|c|c|}
\hline $\mathrm{R}_{\mathrm{e}}{ }^{\mu}(\mathrm{MPa})$ & $\mathrm{A}(\mathrm{MPa})$ & $\mathrm{B}\left(\mathrm{T}^{-1}\right)$ & $\mathrm{R}_{\mathrm{m}}{ }^{\mu}(\mathrm{MPa})$ & $\mathrm{C}(\mathrm{MPa})$ & $\mathrm{D}\left(\mathrm{T}^{-1}\right)$ \\
\hline 434 & 1910 & -0.01405 & 507 & 843 & -0.0094 \\
\hline
\end{tabular}

Dynamic yield stress (strain rate $10^{2} \mathrm{~s}^{-1}$ ) is determined by the method of instrumented Charpy impact test [7]. The load versus time diagram is recorded and the load at general yielding $\mathrm{P}_{\mathrm{GY}}$ is evaluated. Fracture energy is defined on load displacement diagram until load at initiation, which is different from maximum load. Dynamic yield stress is then obtained using the Green and Hundy solution [8].

$$
P_{G Y}=L \frac{R_{e}(W-a)^{2} B}{4 W}
$$

where $\mathrm{W}$ is specimen's width, B thickness, a is notch depth, and L is the constraint factor with a value of $\mathrm{L}=1.31$.

Results are fitted with Equations (3) and (4) and values of constants are reported in Table 4. One notes that higher loading rate leads to higher yield stress and transition temperature.

Table 4. Values of constants of Equations (3) and (4) for API 5L X65 pipe steel for dynamic loading.

\begin{tabular}{|c|c|c|c|c|c|}
\hline $\mathrm{Re}^{\mu, \mathrm{d}}(\mathrm{MPa})$ & $\mathrm{A}_{\mathrm{d}}(\mathrm{MPa})$ & $\mathrm{B}_{\mathrm{d}}\left(\mathrm{T}^{-1}\right)$ & $\mathrm{Rm}^{\mu, \mathrm{d}}(\mathrm{MPa})$ & $\mathrm{C}_{\mathrm{d}}(\mathrm{MPa})$ & $\mathrm{D}_{\mathrm{d}}\left(\mathrm{T}^{-1}\right)$ \\
\hline 541 & 1802 & -0.0012226 & 658 & 691 & 0.010276 \\
\hline
\end{tabular}

\subsection{Brittle to ductile transition temperature for Charpy $\mathbf{V}$ test $\mathbf{T}_{\mathbf{K} 27}$}

However, despite the introduction during the 1960's of Fracture Mechanics tests to measure fracture resistance of materials, the practice of the Charpy impact test remains. It always gives a simple and inexpensive method to classify materials by their resistance to brittle fracture. The current trend is also to use these tests to measure fracture toughness and ductile tearing strength. The comparison of the two methods requires taking into account two major differences:

- Charpy test uses a notched sample, and fracture mechanics tests use a pre-cracked specimen (but a pre-cracked Charpy specimens may also be used).

- Charpy tests are dynamic tests, although the conventional fracture mechanics tests are static ones.

Charpy energy versus temperature curve is fitted with the following relationship:

$$
K_{C V}=A_{C V}+B_{C V} \tanh \left[\frac{\left(T-D_{C V}\right)}{C_{C V}}\right]
$$

where $A_{C V}, B_{C V}, C_{C V}$, and $D_{C V}$ are constants. $A_{C V}$ represents Charpy energy at transition temperature $\mathrm{D}_{\mathrm{cv}}, \mathrm{B}_{\mathrm{CV}}$ is the energy jump between brittle and ductile plateaus and $2 \mathrm{C}_{\mathrm{CV}}$ is the temperature range of the Charpy energy transition. Transition temperature has been determined at conventional level of 27 joules and called $T_{K 27}$ and also at half the jump between brittle and ductile plateau $\left(\mathrm{T}_{\mathrm{K} 50}=\mathrm{D}_{\mathrm{CV}}\right)$. Charpy impact tests have been performed on 
API 5L X65 pipe steel with standard Charpy specimens at temperature range $\left[-196^{\circ} \mathrm{C}\right.$ up to $\left.20{ }^{\circ} \mathrm{C}\right]$.

Experimental data are reported on Figure 2. Charpy energy and fracture aspects reveal the two failure modes below and above the transition temperature. Data are fitted according to Equation (6). Values of the four constants $\mathrm{A}_{\mathrm{CV}}, \mathrm{B}_{\mathrm{CV}}, \mathrm{C}_{\mathrm{CV}}$ and $\mathrm{D}_{\mathrm{CV}}$ are reported in Table 5 as well as the transition temperatures $\mathrm{T}_{\mathrm{K} 27}$ and $\mathrm{T}_{\mathrm{K} 50}$.

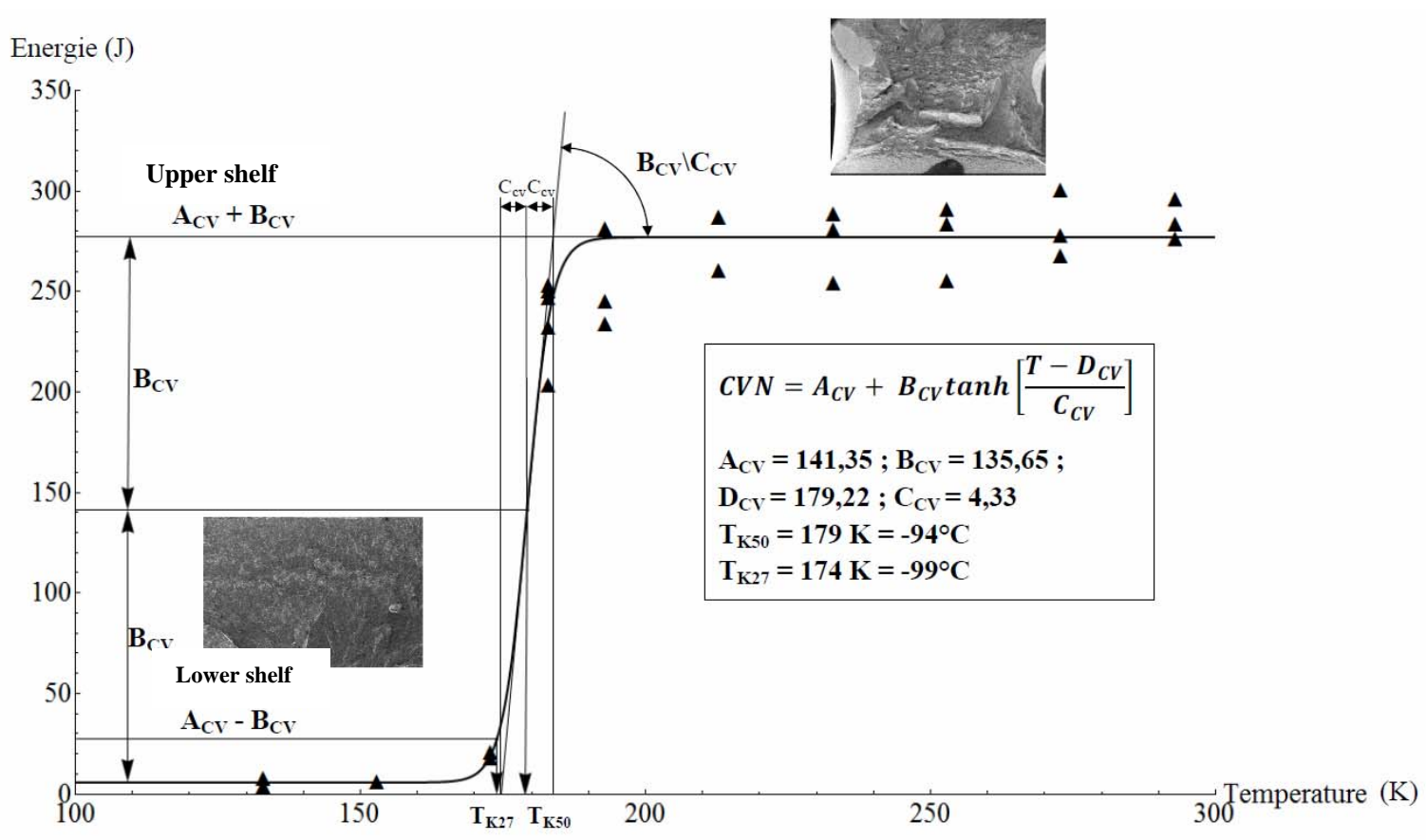

Figure 2. Charpy energy versus temperature curve for API 5L X65 pipe steel and values of parameters of Equation (6).

Table 5. Values of constants of Equation (6) for API 5L X65 pipeline steel

\begin{tabular}{|c|c|c|c|c|c|}
\hline $\mathrm{A}_{\mathrm{CV}}(\mathrm{J})$ & $\mathrm{B}_{\mathrm{CV}}(\mathrm{J})$ & $\mathrm{C}_{\mathrm{CV}}(\mathrm{K})$ & $\mathrm{D}_{\mathrm{CV}}(\mathrm{K})$ & $\mathrm{T}_{\mathrm{K} 27}(\mathrm{~K})$ & $\mathrm{T}_{\mathrm{K} 50}(\mathrm{~K})$ \\
\hline 141.35 & 135.65 & 4.33 & 179.22 & 174 & 179 \\
\hline
\end{tabular}

\subsection{Fracture toughness transition temperature $\mathbf{T}_{\mathbf{0}}$}

Fracture toughness $\mathrm{K}_{\mathrm{IC}}$ evolution versus temperature for brittle and quasi-brittle fracture can be modelled through plasticity-temperature relationship since the fracture process needs a preliminary yielding. Plasticity is a thermally activated phenomenon which follows Arrhenius law. Fracture toughness versus temperature from brittle plateau to transition foot is given by the following Equation 7:

$$
K_{I C}=K_{\min }+E \exp (F T)
$$

$\mathrm{K}_{\min }$ is the fracture toughness threshold, $\mathrm{E}$ and $\mathrm{F}$ are constants and $\mathrm{T}$ is the temperature in Kelvin. Transition temperature called $\mathrm{T}_{0}$ is defined conventionally for a fracture toughness of $100 \mathrm{MPa} \sqrt{\mathrm{m}}$. 
Statistical methods are used to predict the transition toughness curve and specified tolerance limits for 1T specimens of the tested material. The standard deviation of the data distribution is a function of Weibull slope and median $\mathrm{K}_{\mathrm{Jc}}[9]$ :

$$
K_{J c(\text { median })}=30+70 \exp \left[0.019\left(T-T_{0}\right)\right]
$$

in which $T_{0}$ is the temperature associated with the fracture toughness value of $100 \mathrm{MPa} \sqrt{\mathrm{m}} . \mathrm{T}_{0}$ is a characteristic parameter of the material which depends on loading rate. If fracture toughness is plotted versus the reduced temperature $\left(T-\mathrm{T}_{0}\right)$, the material curve is then independent of the loading rate.

Fracture toughness tests have been performed according to standard with CT specimens in the temperature range $[128-293 \mathrm{~K}]$. Fracture toughness data are plotted versus temperature in K and fitted according to Equation 7 from the brittle plateau to transition regime in Figure 3.

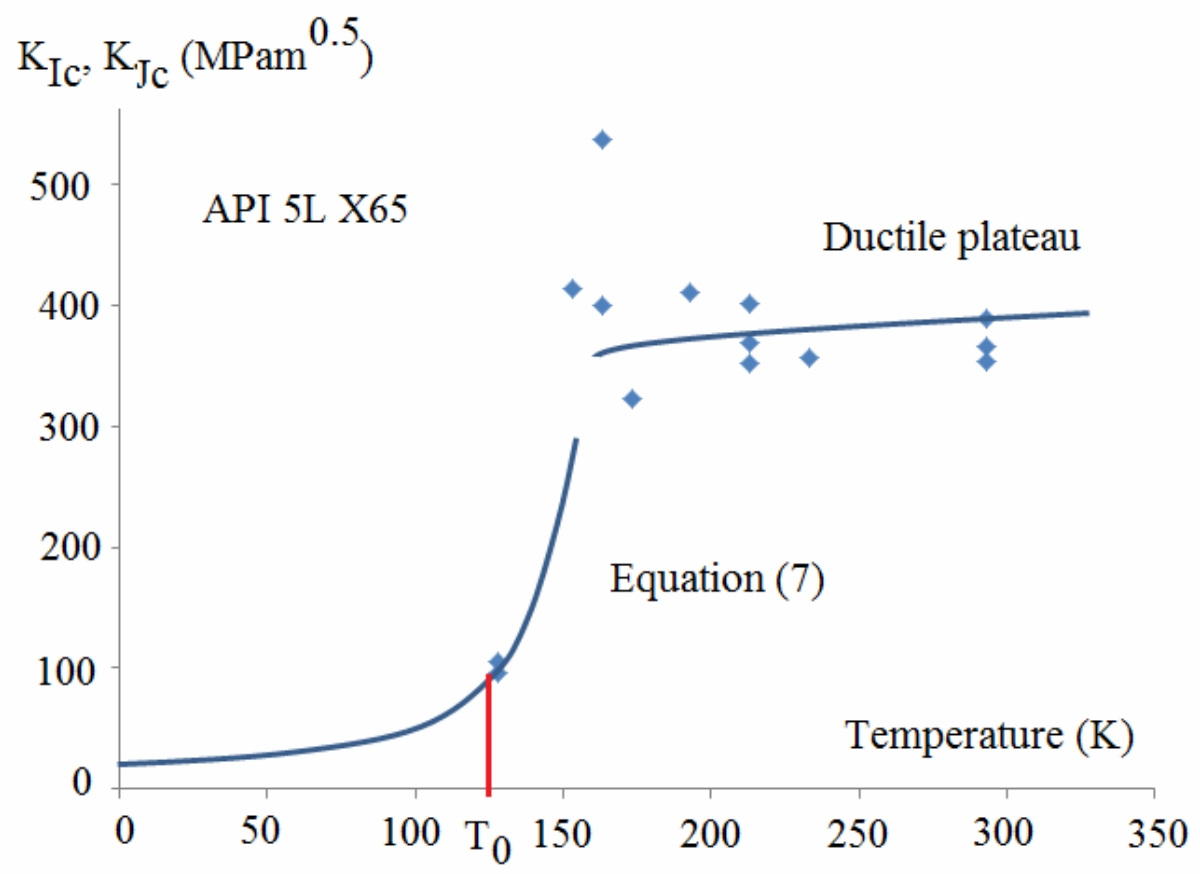

Figure 3. Evolution of fracture toughness versus temperature for API 5L X65 pipeline steel.

Transition temperature $T_{0}$ is obtained according to two methods, which are reported in Table 6:

- $\mathrm{T}_{0.1}$ after fitting experimental data and determining the corresponding temperature to $\mathrm{K}_{\mathrm{Jc}}=100 \mathrm{MPa} \sqrt{\mathrm{m}}$,

- $\mathrm{T}_{0.2}$ using the following empirical relationship in Equation 9 between transition temperatures $\mathrm{T}_{\mathrm{K} 27}$ and $\mathrm{T}_{0}$

$$
T_{0,2}=T_{K 27}-18^{\circ} \mathrm{C}
$$

Table 6. Different values of transition temperature $\mathrm{T}_{0}$.

\begin{tabular}{|c|c|}
\hline $\mathbf{T}_{\mathbf{0 . 1}}\left({ }^{\circ} \mathbf{C}\right)$ & $\mathbf{T}_{\mathbf{0 . 2}}\left({ }^{\circ} \mathbf{C}\right)$ \\
\hline-128 & -117 \\
\hline
\end{tabular}




\section{DISCUSSION}

A pragmatic, engineering approach to assess the fracture integrity of cracked or notched structures requires that constraints in the test specimen approximate that of the structure to provide an "effective" toughness for use in a structural integrity assessment. Constraint effect can be represented by stress triaxiality, Q parameter $[10,11]$ or T-stress [12]. Here constraint is measured by T-stress which is defined by:

$$
T=\left(\sigma_{x x}-\sigma_{y y}\right)_{y=0, \theta=0}
$$

Term $\mathrm{T}$ represents a tension (or compression) stress. Positive T-stress strengthens the level of crack tip stress triaxiality and leads to high crack tip constraint while negative T-stress leads to a loss of constraint.

The volumetric method [2] is employed to calculate the notch fracture toughness and to estimate the effective T-stress ahead of the notch tip. It is assumed, according to the mesofracture principle, that the fracture process requires a physical volume. This assumption is supported by the fact that fracture resistance is affected by the loading mode, specimen geometry and scale effect. To explain these effects, it is necessary to take into account the stress value and the stress gradient in all neighbouring points within the fracture process volume. This volume is assumed to be quasi-cylindrical with a fracture process zone of similar shape. The diameter of this cylinder is called the "effective distance". This procedure leads to a local fracture criterion based on two parameters, namely, the effective distance $\mathrm{X}_{\mathrm{ef}}$ and the effective stress $\sigma_{\text {ef. }}$.

Due to the fact that T-stress in the fracture process zone is not constant, it is also assumed to be determined by averaging the T-stress distribution over the effective distance according to a line method (Eq. 11):

$$
T_{e f}=\frac{1}{X_{e f}} \int_{0}^{X_{e f}} T_{x x}(r) \Phi(r) \cdot d r
$$

where $T_{x x}(r)=\left(\sigma_{x x}(r)-\sigma_{y y}(r)\right)_{\theta=0}$

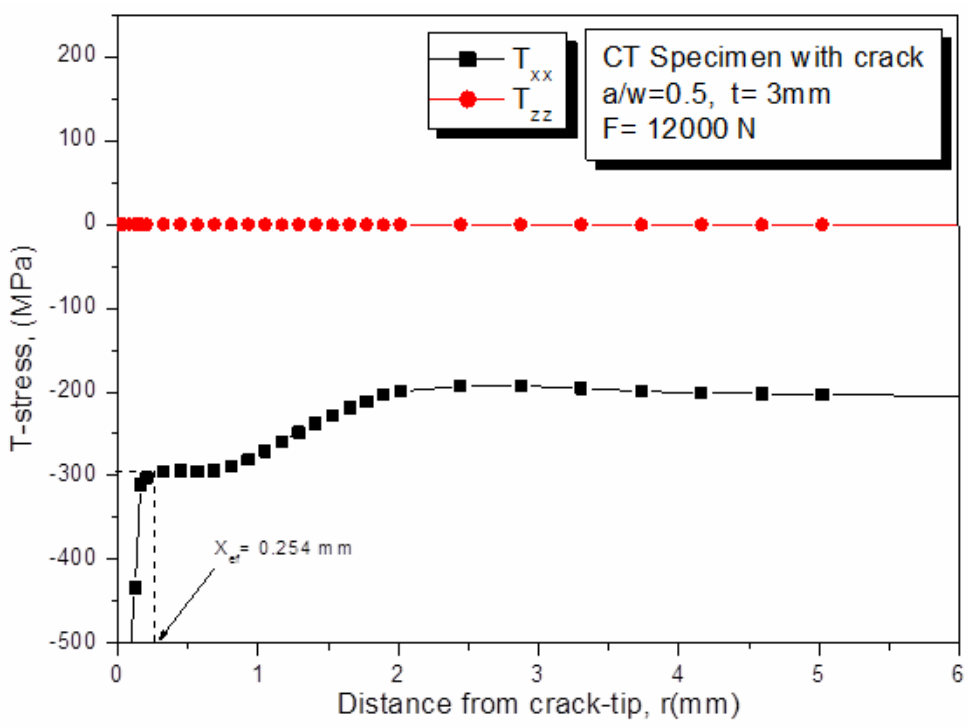

Figure 4. $\mathrm{T}_{\mathrm{xx}}$ and $\mathrm{T}_{\mathrm{zz}}$ distributions ahead crack tip ; CT specimen.

Stress distribution ahead of crack tip has been computed for CT specimens by finite element method using ABAQUS code. In addition, T-stress is determined by the stress difference 
method i.e. the difference between the opening stress and the stress acting parallel to the crack plane. $\sigma_{x x}$ was calculated in the direction $\theta=180^{\circ}$ (i.e., in the crack rear back direction), and the T-stress was defined as the value of $\sigma_{x x}$ in region where this value is constant see fig 4 . Stress distribution is computed with stress strain behaviour at transition temperature where material is quasi elastic. Therefore $T$ stress is not sensitive to temperature.

For each test, critical load has been chosen at transition temperature at which brittle fracture is assumed under linear elastic behaviour. The considered T-stress value is the effective value given by Equation (11) for CT and Charpy specimens. For tensile specimen, T-stress is simply the stress difference $\left(\sigma_{\mathrm{xx}}-\sigma_{\mathrm{yy}}\right)$ using a Poisson ratio equal to $v=0.3$. Table 7 summarizes values of T-stress and associated transition temperature.

Transition temperatures obtained with the 3 different specimens are plotted against temperature and reported in Figure 5. One notes a linear increase of transition temperature with T-stress according to the following relationship:

$$
T_{t}=0.0607 T_{e f}+182
$$

where $T_{t}$ is the transition temperature in Kelvin and $T_{\text {ef }}$ the effective $\mathrm{T}$-stress in MPa. Transition temperature is not intrinsic to material. It decreases with loss of constraint and one notes that the choice of $\mathrm{T}_{\mathrm{K} 27}$ as reference temperature in Equation (2) is the most conservative.

Table 7. Specimen geometry T-stress and associated transition temperature.

\begin{tabular}{|l|c|c|c|}
\hline Specimen & Charpy & CT & Tensile \\
\hline $\mathrm{T}_{\mathrm{ef}}(\mathrm{MPa})$ & -220 & -330 & -998 \\
\hline Transition Temperature $(\mathrm{K})$ & 174 & 156 & 123 \\
\hline
\end{tabular}

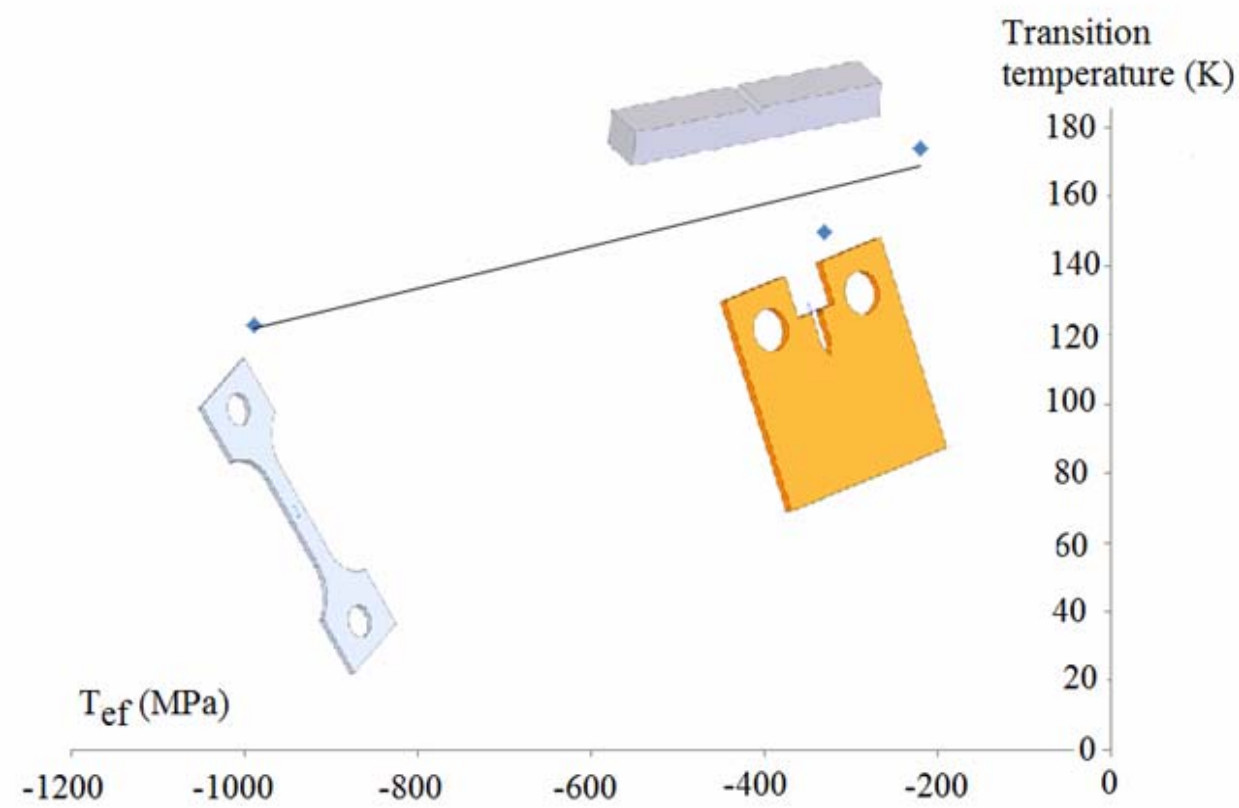

Figure 5. Evolution of transition temperature with effective $\mathrm{T}$-stress $\left(\mathrm{T}_{\mathrm{ef}}\right)$. 
Figure 8 allowed to determine a transition temperature relative to the investigated component, i.e., a transition temperature corresponding to the same constraint as the component at failure. For that purpose, it is necessary to obtain the "material master curve" which is the relationship between fracture toughness and constraint and effective $T$-stress $\left(\mathrm{T}_{\mathrm{ef}}\right)$ at critical pressure for a test according to the procedure described in [13].

Unfortunately, these data are not yet available for X 65 and an estimation has been evaluated on the basis of the API 5L X52 pipe steel and a pipe diameter of $610 \mathrm{~mm}$ and thickness equal to $5.8 \mathrm{~mm}$. The pipe exhibits a surface notch with a notch angle $\varphi=0$, a notch radius $\rho=0.25$ $\mathrm{mm}$ and a notch depth (a) to thickness (t) ratio equal to $\mathrm{a} / \mathrm{t}=0.5$. From that, the constraint range is estimated between $-450 \mathrm{MPa}$ and $-550 \mathrm{MPa}$.

The average component transition temperature $\mathrm{T}_{\text {comp }}$ is deduced from the master curve and evaluated to $150 \mathrm{~K}$ (see Figure 6). This temperature is lower than $\mathrm{T}_{\mathrm{K} 27}$ transition temperature of $24 \mathrm{~K}$; this value represents the degree of conservatism of using transition temperature deduced from Charpy specimens. The safety temperature range between the depressurisation temperature plus a temperature allowance and the component temperature is $35 \mathrm{~K}$, which is enough, allowing to consider that API 5L X65 could be used for dense $\mathrm{CO}_{2}$ transportation.

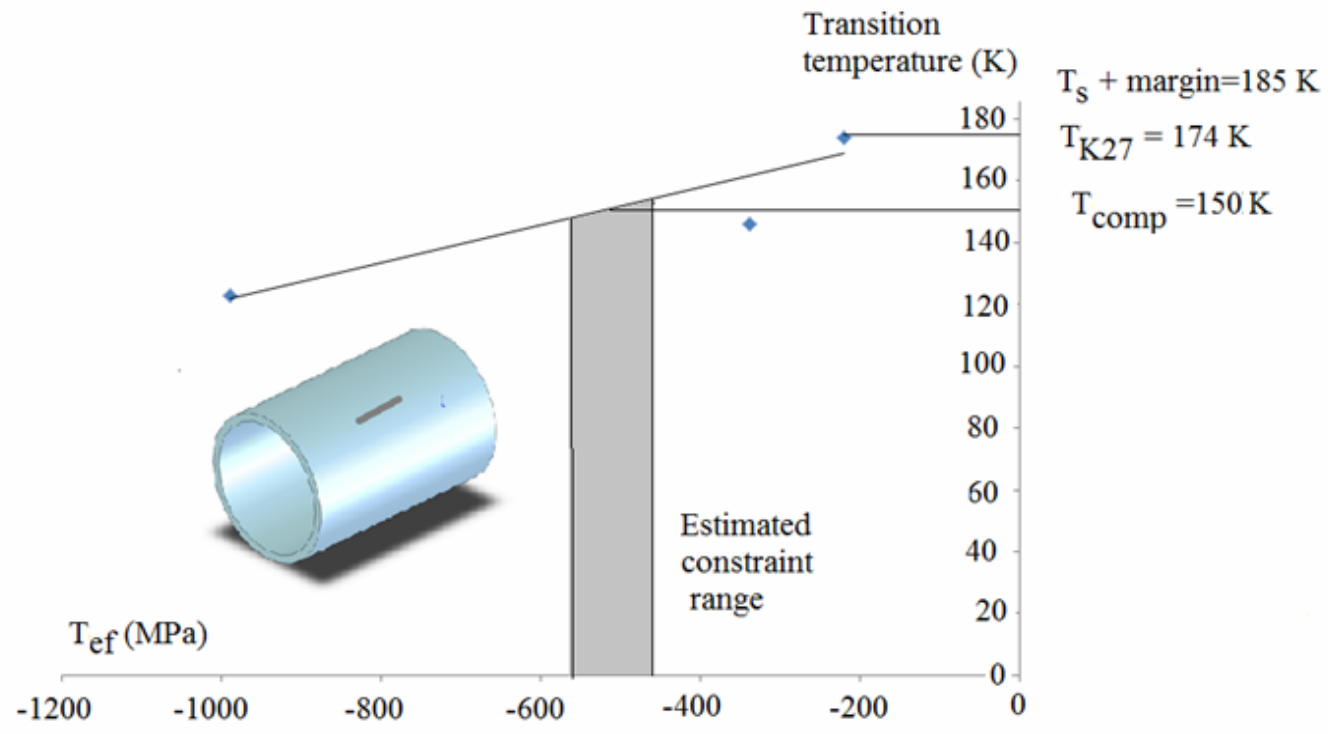

Figure 6. Estimation of component transition temperature from the master curve $\left(\mathrm{T}_{\mathrm{t}}=\mathrm{f}(\right.$ constraint $\left.)\right)$.

\section{CONCLUSION}

In order to select a steel for transportation of dense $\mathrm{CO}_{2}$, transition temperatures $\mathrm{T}_{\mathrm{t}}$ (from tensile test), $\mathrm{T}_{\mathrm{K} 27}$ and $\mathrm{T}_{\mathrm{K} 50}$ (from Charpy test)and $\mathrm{T}_{\mathrm{K} 100}$ (from fracture mechanics test) have been determined on an API 5L X65 steel. These transition temperatures have been reported versus a constraint parameter, e.g. T-stress, in a master curve. Differences between different brittle-ductile transition temperatures and temperature corresponding to T-stress acting in a pipe submitted to internal pressure on the master curve, give an estimation of the conservatism of the chosen transition temperature.

Based on this methodology the selected API 5L X65 pipeline steel could be used for dense $\mathrm{CO}_{2}$ transportation since the experimental and calculated transition temperatures are lower than the expected $-80{ }^{\circ} \mathrm{C}$ following a rapid decompression of dense $\mathrm{CO}_{2}$ pipeline rupture. The most conservative transition temperature was obtained by Charpy impact test $T_{\mathrm{K} 27}$, which is lower than depressurisation temperature plus a temperature allowance. 


\section{References}

[1] Dooley, J. J., Dahowski, R. T., Davidson, C. L. (2009). Comparing existing pipeline networks with the potential scale of future U.S. $\mathrm{CO}_{2}$ pipeline networks, Energy Procedia, 1, 1595-1602.

[2] Pluvinage, G. (2007). General approaches of pipeline defect assessment in Safety, Reliability and Risks associated with water, oil and Gas pipelines, Edited by Pluvinage, G. and Elwany, M., Springer, 1-22.

[3] API 579-1/ASME FFS-1 (2007). Fitness for Service, American Society of Mechanical Engineers, Houston.

[4] Hadj Meliani, M., Matvienko, Y.G., and Pluvinage, G. (2011). Corrosion defect assessment on pipes using limit analysis and notch fracture mechanics, Engineering Failure Analysis, 18, 271-283.

[5] Kloster, G., Probst-Hein, M. (2012). X65 steel for seamless line pipe and risers for onand offshore projects, Vallourec and Mannesmann Tubes, Düsseldorf, Accessed on June 8, 2012 at www.vmtubes.com.

[6] AFNOR standard: NF EN 10002-1 (1990). Matériaux métalliques. Essai de traction, Association Française de Normalisation, Saint Denis La Pleine.

[7] AFNOR standard: NF EN ISO 14556 (2001). Acier. Essai de flexion par choc sur éprouvette Charpy à entaille en V. Méthode d'essai instrumentée, Association Française de Normalisation, Saint Denis La Pleine.

[8] Green, A. P., and Hundy, B. B. (1956). Initial plastic yielding in notch bend tests, Journal of Mechanics and Physics of Solids, 4, 128-144.

[9] ASTM E1921-11a, (2003). Standard Test Method for Determination of Reference Temperature, $T_{0}$ for Ferritic Steels in the Transition Range, American Society for Testing and Materials, Philadelphia.

[10] Ruggieri, C., Gao, X., and Dodds, R. H., (2000). Transferability of elastic-plastic fracture toughness using the Weibull stress approach: significance of parameter calibration; Engineering Fracture Mechanics, 67, 101-117.

[11] Henry, B. S., Luxmore, A. R. (1997). The stress triaxiality constraint and the Q-value as a ductile fracture parameter, Engineering Fracture Mechanics, 57, pp. 375-390.

[12] Betegon, C., and Hancock, J. W. (1991). Two parameter characteristics of elastic- plastic crack-tip fields, Journal of Applied Mechanics, 58, 104-101.

[13] Hadj Meliani, M., Matvienko, Y. G., Pluvinage, G. (2011). Two-parameter fracture criterion $\left(\mathrm{K}_{\rho, \chi}-\mathrm{T}_{\mathrm{ef}, \mathrm{c}}\right)$ based on notch fracture mechanics, International Journal of Fracture, 167, 173-182. 